\title{
CAPACIDADE PREDATÓRIA E ASPECTOS BIOLÓGICOS DE Chrysoperla externa (Hagen, 1861) (Neuroptera: Chrysopidae) ALIMENTADA COM Rhopalosiphum maidis (Fitch, 1856) (Hemiptera: Aphididae)
}

\author{
Predatory capacity and biological aspects of Chrysoperla externa \\ (Hagen, 1861) (Neuroptera: Chrysopidae) fed on Rhopalosiphum maidis (Fitch, 1856)
}

\author{
Wilson J. Mello e Silva Maia ${ }^{1}$, César Freire Carvalhoº \\ Brígida Souza $^{2}$, Ivan Cruz ${ }^{3}$, Terezinha J. A. Ferreira Maia ${ }^{4}$
}

\begin{abstract}
RESUMO
Objetivou-se estudar alguns aspectos biológicos, a capacidade predatória e a resposta funcional de larvas de Chrysoperla externa (Hagen) alimentadas com ninfas de segundo e terceiro ínstares do pulgão Rhopalosiphum maidis (Fitch), em cinco densidades. Os ensaios foram conduzidos em câmaras climatizadas reguladas a $25 \pm 1^{\circ} \mathrm{C}$, UR de $70 \pm 10 \%$ e fotofase de 12 horas. Para o estudo de biologia e capacidade predatória, o delineamento foi inteiramente casualizado, com cinco repetições e oito indivíduos/repetição, totalizando 40 larvas e, para a resposta funcional, os tratamentos corresponderam a cinco densidades de presa e cinco repetições com dois indivíduos/repetição. As observações foram realizadas às 24,48 horas e no final de cada ínstar. O consumo aumentou proporcionalmente em função do estádio de desenvolvimento da larva, sendo maior no terceiro instar, com 279,1 pulgões, representando aproximadamente $82,0 \%$ do consumo total. Observaram-se uma duração de 11 dias para a fase larval e uma viabilidade de $100 \%$ em todos os estádios de desenvolvimento. Para os três ínstares e fase larval, constatou-se maior consumo e duração em função do aumento da densidade de presas. Verificou-se uma resposta funcional Tipo II para todos os ínstares. Constatou-se, para larvas de segundo e terceiro ínstares, o menor tempo de busca, e o primeiro ínstar apresentou o maior tempo de manuseio.
\end{abstract}

Termos para indexação: Resposta funcional, crisopídeo, pulgão da folha do milho.

\begin{abstract}
The aim of this research was to study the biological aspects, predatory capacity and functional response of the immature stages of Chrysoperla externa (Hagen) fed on the aphid Rhopalosiphum maidis (Fitch), in five densities of prey utilizing nymphs of second and third instars. The experiments were carried out in climatic chambers at $25 \pm 1{ }^{\circ} \mathrm{C}, \mathrm{RH}$ of $70 \pm$ $10 \%$ and 12-h photophase. For studying the biology, the design was completely randomized with five replicates and eight insects/replicate, having a total of 40 larvae and, for the functional response, the treatments were composed by five densities of prey and five replicates, with two insects/replicate. The readings were done at 24, 48 hours and in the end of each instar. The consumption increased proportionally to the function of the development stages of the larva, with a higher one in the third instar with 279.1 aphids, representing about $82 \%$ of the consumption. A length of 11 days for the larval stage was observed, and a survival rate of $100 \%$ in all stages. It was possible to observe a higher consumption and length for the three instars and larval stage, related to the increase in prey densities. The functional response of Type II was observed for all instars. The lowest searching time for the average prey density was verified for second and third instars larvae, and the first instar presented the higher handling time.
\end{abstract}

Index terms: Functional response, green lacewing, corn leaf aphid.

(Recebido para publicação em 24 de abril de 2003 e aprovado em 13 de dezembro de 2004)

\section{INTRODUÇÃO}

Artrópodes-praga são fatores limitantes à exploração agrícola. A infestação pelo pulgão Rhopalosiphum maidis (Fitch, 1856) em milho inicia em plantas isoladas, disseminando-se mediante pequenas colônias durante a fase de desenvolvimento vegetativo e, principalmente, próximo ao lançamento do pendão, quando as folhas encontram-se enroladas, multiplicando-se com facilidade, mas sem importância econômica direta (GASSEN, 1996). Todavia, sob alta densidade populacional no pré-florescimento, pode ocasionar perda econômica, principalmente se essa infestação estiver associada ao estresse hídrico e as plantas estiverem nos estádios correspondentes à iniciação floral e desenvolvimento da inflorescência, período de fertilização e enchimento de grãos (EVERLY, 1960; HONĚK, 1990, 1991; MAGALHÃES et al., 1995).

1. Engenheiro Agrônomo, Dr., Departamento de Biologia Vegetal e Fitossanidade, Universidade Federal Rural da Amazônia/UFRA - 66077-830 - Belém, PA.

2. Professores do Departamento de Entomologia, Universidade Federal de Lavras/UFLA - Caixa Postal 3037 - $37200-000$ - Lavras, MG.

3. Pesquisador, Embrapa Milho e Sorgo, Caixa Postal 151 - 35701-970 - Sete Lagoas, MG.

4. Técnico em Laboratório, UFRA. 
Os predadores são, muitas vezes, agentes eficazes na regulação da densidade populacional desses organismos, destacando-se os Chrysopidae, mundialmente reconhecidos pela sua ocorrência em diversos agroecossistemas (SENIOR e MCEWEN, 2001). A fauna Neotropical de crisopídeos é uma das mais ricas, com 21 gêneros e mais de 300 espécies (BROOKS, 1994; ALBUQUERQUE et al., 2001). O gênero Chrysoperlas steinmann, 1964, possui vasta distribuição geográfica, incluindo 36 espécies, com maior concentração na Região Holoártica. No continente americano, encontra-se Chrysoperla externa (Hagen, 1861), cuja ocorrência tem sido registrada em diversas regiões no Brasil.

Atributos como grande capacidade de busca e voracidade das larvas, alto potencial reprodutivo, tolerância a determinados grupos de inseticidas e a facilidade de criação em laboratório favorecem o uso de $C$. externa em programas de controle biológico. Entretanto, há necessidade de estudos sobre sua biologia e interação com insetos-praga como subsídio para programas de controle biológico.

A resposta funcional dos inimigos naturais a mudanças na densidade da presa é uma forma de constatação da variação na relação entre esses organismos, em que um aumento na disponibilidade de presas pode levar o predador a um aumento do consumo (SOLOMON, 1949; O'NEIL, 1990). A resposta funcional e a numérica são componentes básicos da predação e originários da relação entre as densidades de presas e de predadores, podendo afetar diretamente o número de indivíduos predados (HOLLING, 1961).

A falta de conhecimento da dinâmica populacional das pragas e de seus inimigos naturais tem sido o principal entrave ao progresso na prática de manipulação dos agroecossistemas. A preferência dos crisopídeos por determinadas presas, densidade e qualidade nutricional da presa, ou sua habilidade na captura desses organismos, podem ser fatores importantes nas liberações inundativas e crucial nas inoculativas (DAANE, 2001). Assim, a manipulação do habitat como tática de uso de crisopídeos no manejo de pragas requer o conhecimento da biologia das espécies envolvidas.

Com base na necessidade de pesquisas relacionadas à interação predador/presa, com este trabalho objetivou-se estudar alguns aspectos biológicos das fases imaturas, a capacidade predatória e a resposta funcional de C. externa alimentada com o pulgão $R$. maidis em diferentes densidades.

\section{MATERIAL E MÉTODOS}

Adultos de C. externa coletados no campus da Universidade Federal de Lavras - UFLA foram acondicionados em gaiolas cilíndricas de $\mathrm{PVC}$ de $20 \mathrm{~cm}$ de altura por $20 \mathrm{~cm}$ de diâmetro revestidos com papel-filtro branco e alimentados com lêvedo de cerveja + mel (1:1). As unidades foram mantidas em sala climatizada a $25 \pm 1{ }^{\circ} \mathrm{C}$, UR de $70 \pm 10 \%$, fotofase de 12 horas. A partir dessa criação de manutenção, individualizaram-se 40 ovos de C. externa em tubos de vidro de $2,5 \mathrm{~cm}$ de diâmetro por $8,5 \mathrm{~cm}$ de altura, vedados com filme de PVC e perfurados para aeração. As larvas foram alimentadas ad libitum com ovos da traça Anagasta kuehniella (Zeller, 1879) (Lepidoptera: Pyralidae) e com o pulgão Schizaphis graminum (Rondani, 1852), provenientes de uma criação do próprio laboratório.

Às larvas dos experimentos foram oferecidas ninfas de $R$. maidis, também oriundas de uma criação em laboratório. Esses afídeos foram multiplicados de acordo com metodologia desenvolvida por Fonseca (2002), utilizando a cultivar de milho BRS 3133 cultivada em casa-de-vegetação. Padronizou-se o tamanho dos pulgões colocando-se 40 adultos em uma unidade de criação contendo uma secção foliar de milho, para produção de ninfas. Os adultos foram retirados dois dias após e, no quarto dia, utilizaram-se as ninfas de terceiro e quarto ínstares na instalação dos ensaios.

Para o estudo da capacidade predatória e resposta funcional de C. externa, efetuaram-se ensaios preliminares adotando a metodologia de Fonseca et al. (2000), visando a determinar o número médio de afídeos consumidos diariamente por ínstar. Para isso, criaram-se 10 larvas do crisopídeo em uma densidade de presas acima da capacidade diária de consumo, obtendo-se uma média de 6, 20 e 100 pulgões consumidos no primeiro, segundo e terceiro estádios, respectivamente. Utilizaram-se cinco densidades de pulgões, sendo duas abaixo e duas acima do consumo médio por ínstar (Tabela 1).

As observações foram realizadas diariamente até a emergência dos adultos. Avaliaram-se a duração e a viabilidade de cada ínstar, das fases de larva, pré-pupa, pupa e do período de larva a adulto, nas cinco densidades.

Para avaliar o tempo de busca e de manuseio da presa pelo predador, utilizou-se a metodologia de Fonseca et al. (2000). O tempo de busca correspondeu ao período em que o predador ficou exposto à presa até a sua captura. O período em que ele ficou em contato com a presa, alimentando-se dela, correspondeu ao tempo de manuseio. 
TABELA 1 - Densidades de Rhopalosiphum maidis oferecidos diariamente às larvas de primeiro, segundo e terceiro ínstares de Chrysoperla externa. Temperatura de $25 \pm 1^{\circ} \mathrm{C}$, UR $70 \pm 10 \%$ e fotofase de 12 horas.

\begin{tabular}{cccc}
\hline \multirow{2}{*}{ Densidade do Pulgão } & \multicolumn{3}{c}{$\mathbf{N}^{\mathbf{0}}$ de pulgões/ínstar } \\
\cline { 2 - 4 } & $\mathbf{1}^{\mathbf{0}}$ & $\mathbf{2}^{\mathbf{0}}$ & $\mathbf{3}^{\mathbf{0}}$ \\
\hline 1 & 2 & 10 & 30 \\
2 & 4 & 15 & 65 \\
3 & 6 & 20 & 100 \\
4 & 8 & 25 & 135 \\
5 & 10 & 30 & 170 \\
\hline
\end{tabular}

Para o estudo da capacidade predatória de larvas de C. externa, o delineamento foi inteiramente casualizado, com cinco repetições e oito larvas/repetição, totalizando 40 insetos. Avaliou-se o número de ninfas predadas diariamente até o final de cada estádio. Após esse procedimento e higienização dos tubos, forneceu-se novamente às larvas o mesmo número de presas, correspondente ao ínstar considerado. Os dados foram submetidos à análise de variância e as médias, comparadas pelo teste de Scott e Knott a 5\%.

A avaliação da resposta funcional foi realizada experimentalmente usando-se o mesmo tipo de delineamento, com cinco densidades do afídeo por ínstar do predador em cinco repetições com duas larvas, totalizando dez larvas por densidade e 50 no total. Os dados referentes ao tempo de busca e manuseio foram submetidos à análise de variância, sendo as médias comparadas pelo teste de Scott e Knott a 5\%, e em função do caráter quantitativo das variáveis, fez-se também a regressão polinomial.

\section{RESULTADOS E DISCUSSÃO}

\section{Aspectos biológicos das fases imaturas de Chrysoperla externa}

A duração do primeiro, segundo, terceiro ínstares e fase larval de C. externa, quando a presa foi oferecida nas cinco densidades de $R$. maidis, foi de 3,$6 ; 3,1$; 4,3 e 11,0 dias, respectivamente (Figura 1). Albuquerque et al. (1994), alimentando larvas de C. externa com ovos de Sitotroga cerealella (Olivier, 1819) (Lepidoptera: Gelechiidae) e o pulgão Myzus persicae (Sulzer, 1776), constataram, para a duração dos três ínstares e fase larval em condições ambientais semelhantes, resultados próximos aos obtidos nesta pesquisa.

López (1996), trabalhando com essa mesma espécie de crisopídeo em temperatura próxima a $25^{\circ} \mathrm{C}$ e utilizando como presa o pulgão Rhodobium porosum (Sanderson, 1900), Maia et al. (2000), utilizando como presa o pulgão $S$. graminum, também constataram resultados semelhantes em todos os ínstares e fase larval de C. externa. As variações detectadas na duração de cada estádio e da fase larval, entre os resultados obtidos e os registrados na literatura, podem ser atribuídas ao tipo de presa oferecida, influência da temperatura, umidade relativa, disponibilidade e qualidade do alimento.

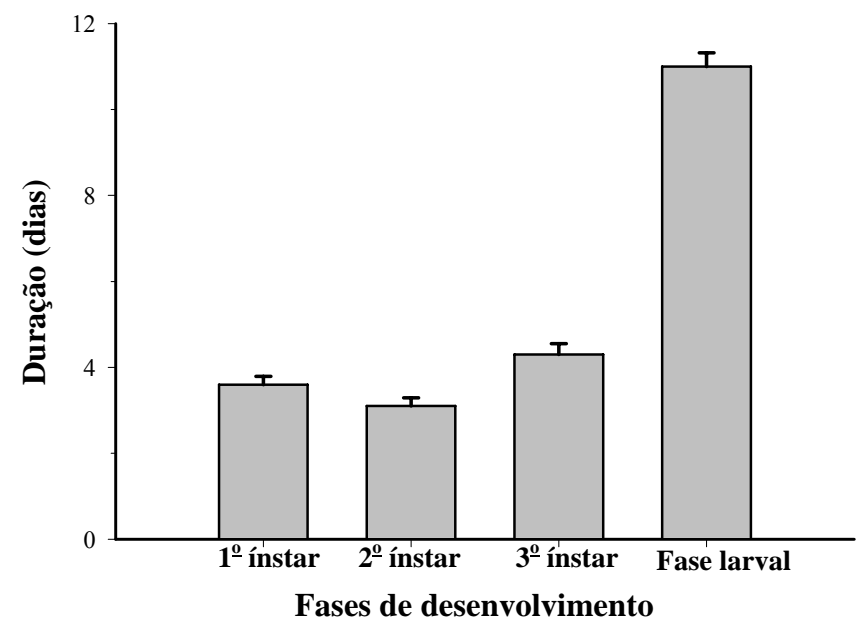

FIGURA 1 - Duração dos ínstares e fase larval de Chrysoperla externa alimentada com Rhopalosiphum maidis. Temperatura de $25 \pm 1^{\circ} \mathrm{C}$, UR $70 \pm 10 \%$ e fotofase de 12 horas. 
Com relação à capacidade predatória de larvas de C. externa, observou-se que, no primeiro ínstar, o consumo foi maior no intervalo entre 24 e 48 horas, em relação às primeiras 24 horas após a eclosão, passando de 4,8 para 13,8 pulgões, representando um aumento de cerca de $187 \%$. Nos ínstares subseqüentes, verificou-se o inverso, ocorrendo maior consumo nas primeiras 24 horas após a ecdise, constatando-se reduções próximas a $38 \%$ e $112 \%$, respectivamente, resultado também observado para a fase larval completa. O consumo total de R. maidis por larvas de segundo ínstar durante as 24 horas após a ecdise foi de cerca de 18 e, para o terceiro, de 135 , reduzindo para cerca de 10 e 63 pulgões, respectivamente, no intervalo entre 24 e 48 horas (Figura 2).

Quando se observou o consumo médio diário para os três ínstares e fase larval (Figura 3), constatou-se um aumento de maneira concomitante ao desenvolvimento da larva, com 6,1 (7,2\%) no primeiro ínstar, $13,0(15,4 \%)$ no segundo ínstar e 65,4 pulgões/dia (77,4\%) no terceiro ínstar, correspondendo a uma média diária de 28,2 pulgões consumidos durante toda a fase larval. Ribeiro (1988) verificou um menor aumento no número médio do pulgão Aphis gossypii Glover, 1877 consumidos diariamente por larvas dessa mesma espécie a $25^{\circ} \mathrm{C}$, constatando-se um aumento de 3,5 vezes para o terceiro ínstar, em relação às larvas de primeiro ínstar. Essa diferença pode estar relacionada com o tamanho, comportamento e qualidade nutricional da presa. De maneira similar, Fonseca et al. (2000) verificaram, para os três ínstares e fase larval de $C$. externa alimentada com S. graminum a $24^{\circ} \mathrm{C}$, um consumo médio diário de 3,$4 ; 10,5 ; 76,7$ e de 29,0 pulgões, respectivamente, evidenciando um aumento superior a vinte vezes entre o consumo no primeiro e terceiro ínstares.

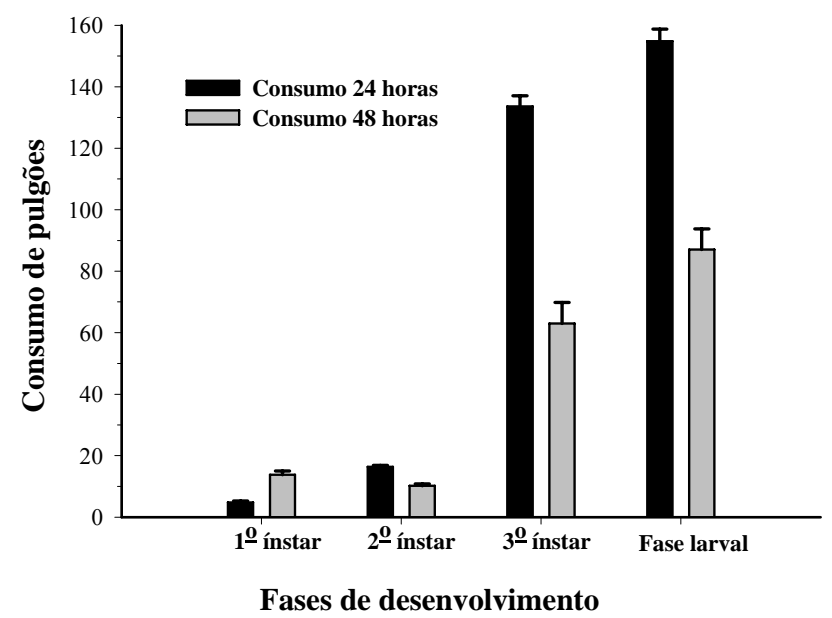

FIGURA 2 - Número médio de Rhopalosiphum maidis consumidos nos três ínstares e fase larval de Chrysoperla externa. Temperatura de $25 \pm 1^{\circ} \mathrm{C}$, UR $70 \pm 10 \%$ e fotofase de 12 horas.
Para o consumo total, verificou-se uma relação direta entre o número de insetos predados e o desenvolvimento larval, atingindo o máximo no terceiro ínstar (Figura 4). Nesse estádio, o consumo foi cerca de $82 \%$ do total verificado para a fase larval, o que também foi observado por Chakrabarti et al. (1991), López (1996), Carvalho et al. (1998) e Fonseca et al. (2000). O número total de presas consumidas no primeiro, segundo, terceiro ínstares e fase larval de C. externa foi de 21,9 ; 40,$1 ; 279,0$ e 341,0 pulgões.

Os resultados verificados neste trabalho, referentes à predação por larvas de primeiro e segundo ínstares, foram menores, quando comparados aos obtidos por Ribeiro (1988) para larvas dessa mesma espécie alimentadas com A. gossypii, a $25^{\circ} \mathrm{C}$. Porém, foram superiores aos verificados por Fonseca et al. (2000), quando as larvas foram mantidas a $24^{\circ} \mathrm{C}$ e alimentadas com o pulgão S. graminum, possivelmente em função do tipo de alimento utilizado.

Segundo Canard (1970, 1973), diferenças encontradas no potencial de predação para uma mesma espécie de crisopídeo podem estar correlacionadas com o tipo de presa e adaptação ao predador, que não apresenta um desenvolvimento satisfatório quando alimentado com algumas espécies de afídeos. Assim, Santa-Cecília et al. (2001) constataram que, apesar da alta viabilidade obtida para os estágios imaturos de C. externa alimentada com a cochonilha Dysmicoccus brevipes (Cockerell, 1893) (Hemiptera: Pseudococcidade), a duração das fases foi prolongada em relação à de larvas alimentadas com ovos de A. kuehniella. De maneira geral, além da espécie de presa, a interação presa/hospedeiro pode refletir diretamente sobre a predação e desenvolvimento do predador. 


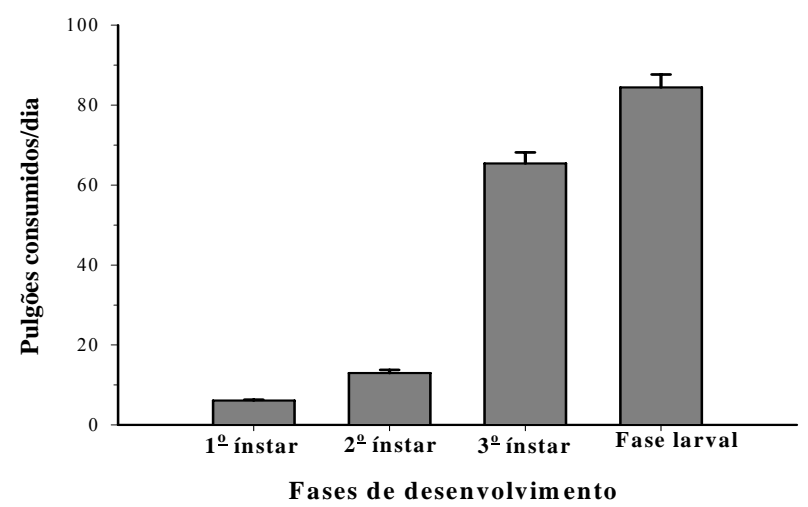

FIGURA 3 - Número médio de Rhopalosiphum maidis consumidos/dia nos três ínstares e fase larval de Chrysoperla externa. Temperatura de $25 \pm 1^{\circ} \mathrm{C}$, UR $70 \pm 10 \%$ e fotofase de 12 horas.

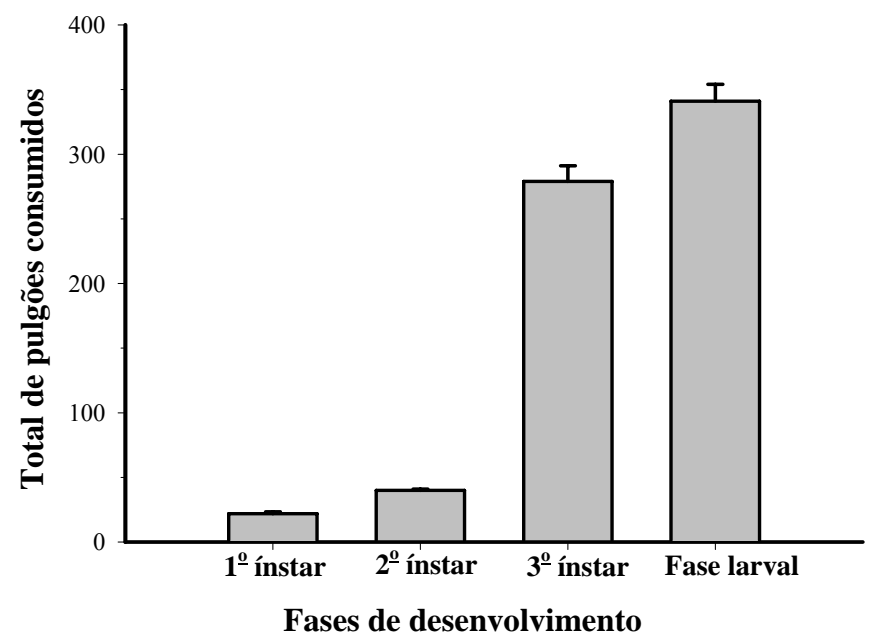

FIGURA 4 - Média do número total de Rhopalosiphum maidis consumidos nos três ínstares e fase larval de Chrysoperla externa. Temperatura de $25 \pm 1^{\circ} \mathrm{C}$, UR $70 \pm 10 \%$ e fotofase de 12 horas.

\section{Resposta funcional, tempo de busca e de ma- nuseio de Chrysoperla externa}

Verificou-se, para as larvas dos três ínstares e fase larval completa, maior consumo em função do aumento na densidade da presa. Nas três maiores densidades, obtiveram-se resultados semelhantes quanto ao número de afídeos predados, diferindo das duas densidades menores, as quais também não variaram significativamente entre si (Figura 5).

Zheng et al. (1993) verificaram, para larvas de Chrysoperla carnea (Stephens, 1836) alimentadas com ovos de A. kuehniella, um consumo cerca de duas vezes maior nas densidades superiores à capacidade predatória, quando comparado às inferiores, aproximando-se dos resul- tados obtidos neste trabalho. Também se aproximaram daqueles encontrados por Fonseca et al. (2000), que observaram uma relação semelhante no consumo de S. graminum por larvas de C. externa em cinco densidades desse afídeo.

No que se refere ao efeito da densidade de R. maidis sobre a velocidade de desenvolvimento de C. externa, verificou-se, de maneira geral, que a duração obtida para a fase larval diminuiu em função do aumento no número de presas (Tabela 2). Na menor densidade, a duração do primeiro ínstar foi maior, evidenciando o efeito significativo da densidade da presa sobre a duração desse estádio. Mas, esse efeito não foi verificado para o segundo ínstar e, para o terceiro, verificou-se que, de um modo geral, a velocidade de desenvolvimento aumentou com o aumento da densidade. 
A duração do terceiro ínstar foi significativamente menor na maior densidade de pulgões, possivelmente em função de o predador poder ser saciado de forma mais rápida e as necessidades energéticas serem supridas com maior velocidade. Não houve efeito significativo da densidade de pulgões sobre a duração das fases de prépupa e pupa; contudo, em relação ao período de larva a adulto, a menor duração foi observada na maior densidade (Tabela 3 ).

Obteve-se uma resposta funcional Tipo II para todos os ínstares (Figura 6), conforme sugerido por Holling (1959), quando foram apresentadas as categorias Tipo I, II e III. Assim, em função do consumo ascendente com o aumento na densidade de pulgões, natureza da curva encontrada e mesmo não se alcançando um patamar característico à regressão obtida, evidenciou uma estabilização quanto à capacidade predatória. Possivelmente, densidades maiores àquelas utilizadas demonstrariam de maneira marcante esse tipo de resposta, diferentemente do Tipo I, em que há uma linearização no consumo.

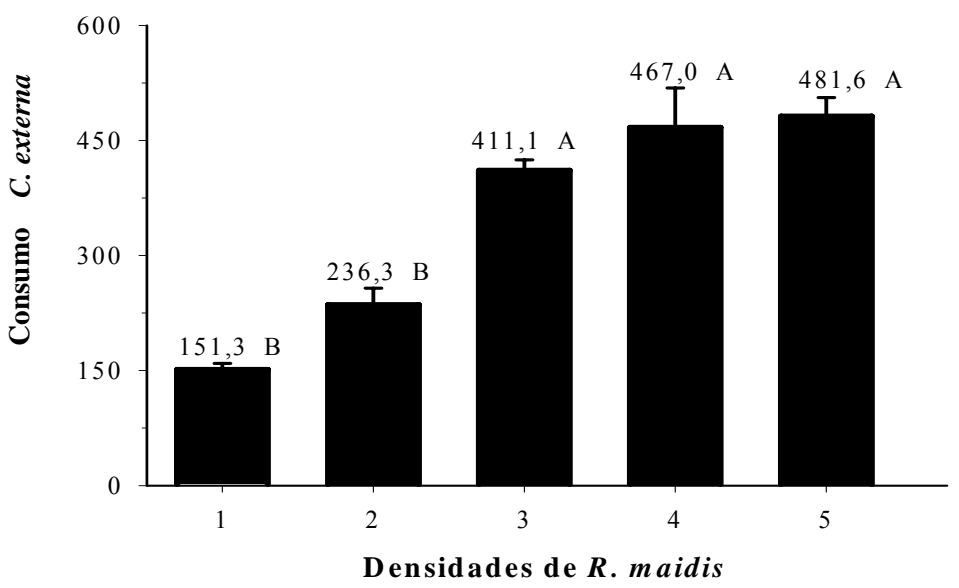

FIGURA 5 - Médias do número total de Rhopalosiphum maidis consumidos por larvas de Chrysoperla externa. Temperatura de $25 \pm 1{ }^{\circ} \mathrm{C}$, UR $70 \pm 10 \%$ e fotofase de 12 horas.

TABELA 2 - Duração em dias ( \pm EP) dos três ínstares e fase larval de Chrysoperla externa, em função da densidade de Rhopalosiphum maidis. Temperatura de $25 \pm 1{ }^{\circ} \mathrm{C}$, UR $70 \pm 10 \%$ e fotofase de 12 horas.

\begin{tabular}{ccccc}
\hline Densidade de presas & \multicolumn{3}{c}{ Duração dos ínstares } & \multirow{2}{*}{ Fase larval } \\
\cline { 2 - 4 } & \multicolumn{1}{c}{$\mathbf{1}^{\mathbf{0}}$} & $\mathbf{2}^{\mathbf{0}}$ & $\mathbf{3}^{\mathbf{0}}$ & \\
\hline 1 & $3,1 \pm 0,2 \mathrm{~A}$ & $3,4 \pm 0,2 \mathrm{~A}$ & $5,0 \pm 0,4 \mathrm{~A}$ & $11,5 \pm 0,2 \mathrm{~A}$ \\
2 & $2,4 \pm 0,2 \mathrm{~B}$ & $3,4 \pm 0,2 \mathrm{~A}$ & $4,0 \pm 0,2 \mathrm{~B}$ & $9,8 \pm 0,1 \mathrm{~B}$ \\
3 & $2,7 \pm 0,1 \mathrm{~B}$ & $3,1 \pm 0,2 \mathrm{~A}$ & $4,5 \pm 0,3 \mathrm{~A}$ & $10,3 \pm 0,2 \mathrm{~B}$ \\
4 & $2,4 \pm 0,2 \mathrm{~B}$ & $3,1 \pm 0,1 \mathrm{~A}$ & $4,5 \pm 0,3 \mathrm{~A}$ & $10,2 \pm 0,5 \mathrm{~B}$ \\
5 & $2,4 \pm 0,2 \mathrm{~B}$ & $3,0 \pm 0,3 \mathrm{~A}$ & $3,3 \pm 0,3 \mathrm{~B}$ & $8,7 \pm 0,5 \mathrm{C}$ \\
\hline F & 3,77 & 0,85 & 3,62 & 9,78 \\
\hline CV (\%)** & 11,7 & 14,6 & 17,7 & 7,1 \\
\hline
\end{tabular}

Médias seguidas pela mesma letra nas colunas não diferem entre si, pelo teste de Scott e Knott a 5\% de probabilidade. $\mathrm{F}$ = Valor do $\mathrm{F}$ da ANOVA; $\mathrm{CV}=$ coeficiente de variação.

Ciênc. agrotec., Lavras, v. 28, n. 6, p. 1259-1268, nov./dez., 2004 
TABELA 3 - Duração em dias ( \pm EP) das fases de pré-pupa, pupa e de larva-adulto de Chrysoperla externa, em função da densidade de Rhopalosiphum maidis. Temperatura de $25 \pm 1{ }^{\circ} \mathrm{C}$, UR $70 \pm 10 \%$ e fotofase de 12 horas.

\begin{tabular}{cccc}
\hline \multirow{2}{*}{ Densidade de Presas } & \multicolumn{3}{c}{ Duração } \\
\cline { 2 - 4 } & Pré-pupa & Pupa & Larva-Adulto \\
\hline 1 & $3,7 \pm 0,1 \mathrm{~A}$ & $8,5 \pm 0,2 \mathrm{~A}$ & $23,7 \pm 0,4 \mathrm{~A}$ \\
2 & $4,2 \pm 0,2 \mathrm{~A}$ & $8,5 \pm 0,3 \mathrm{~A}$ & $22,5 \pm 0,3 \mathrm{~B}$ \\
3 & $3,8 \pm 0,3 \mathrm{~A}$ & $8,1 \pm 0,3 \mathrm{~A}$ & $22,2 \pm 0,2 \mathrm{~B}$ \\
4 & $3,5 \pm 0,3 \mathrm{~A}$ & $8,9 \pm 0,4 \mathrm{~A}$ & $22,6 \pm 0,5 \mathrm{~B}$ \\
5 & $3,4 \pm 0,4 \mathrm{~A}$ & $8,9 \pm 0,5 \mathrm{~A}$ & $21,0 \pm 0,5 \mathrm{C}$ \\
\hline F & 1,21 & 0,88 & 6,98 \\
\hline CV (\%) & 17,2 & 9,3 & 3,6 \\
\hline
\end{tabular}

Médias seguidas pela mesma letra na coluna não diferem entre si, pelo teste de Scott e Knott a 5\% de probabilidade. $\mathrm{F}$ = Valor do $\mathbf{F}$ da ANOVA; $\mathrm{CV}$ = coeficiente de variação.

Esses resultados assemelharam-se aos encontrados por Fonseca et al. (2000) para larvas de C. externa alimentadas com S. graminum, que também verificaram uma resposta funcional Tipo II, evidenciando a adaptação desse predador a diferentes espécies de presas. Mesmo não alcançando um patamar para o consumo de A. gossypii por larvas de Chrysoperla rufilabris (Burmeister, 1839), Nordlung e Morrison (1990) verificaram uma resposta funcional Tipo II. Trabalhando com Chrysoperla côngrua (Walker, 1853) e esse mesmo afídeo como presa, Kabissa et al. (1996) obtiveram o mesmo tipo de resposta funcional. De acordo com Holling (1959), há um aumento significativo no consumo de presas quando fornecidas em densidades mais elevadas, podendo ocorrer uma redução gradativa, até a estabilização. Segundo Garcia (1990), essa "estabilidade" ocorre em função da larva do predador estar saciada, e a partir desse momento, ela não é capaz de consumir uma presa adicional.

Com relação ao tempo de busca e de manuseio, foram maiores para larvas de primeiro ínstar de C. externa em comparação àquelas de segundo e terceiro ínstares (Tabela 4). Esse fato também foi verificado por Fonseca et al. (2000) para larvas dessa mesma espécie, em que, nas maiores densidades de $S$. graminum, ocorreu um aumento na predação, verificando-se um menor tempo de busca e de manuseio em relação ao primeiro ínstar. Possivelmente o aumento na densidade da presa permitiu maior probabilidade de encontro com o predador, levando a uma redução no tempo de busca. Além disso, o maior volume corporal do predador a cada ínstar proporcionou sucção mais rá- pida da hemolinfa e, conseqüentemente, redução no tempo de manuseio.

TABELA 4 - Tempo de busca e de manuseio (minutos e segundos) pelos três ínstares de Chrysoperla externa. Temperatura de $25 \pm 1{ }^{\circ} \mathrm{C}$, UR $70 \pm 10 \%$ e fotofase de 12 horas.

\begin{tabular}{|c|c|c|}
\hline \multirow{2}{*}{ Ínstares } & \multicolumn{2}{|c|}{ Tempo médio } \\
\hline & Busca & Manuseio \\
\hline $1^{\underline{o}}$ & 29'51'a & $31^{\prime} 15^{\prime \prime} \mathrm{a}$ \\
\hline $2^{\underline{o}}$ & 9' $13 " \mathrm{~b}$ & 13 ' $56^{\prime \prime} \mathrm{b}$ \\
\hline $3^{o}$ & 8'23”b & $10 ' 11$ ’b \\
\hline
\end{tabular}

Médias seguidas pelas mesmas letras nas colunas não diferem entre si pelo teste de Scott \& Knott a $5 \%$.

Bergeson e Messina (1998), além de terem verificado para larvas de Chrysoperla plorabunda (Fitch, 1855) preferência aos pulgões Rhopalosiphum padi (Linnaeus, 1758 ) em relação a Diuraphis noxia (Kurdjumov, 1913), constataram menor tempo de manuseio na primeira presa, mesmo quando esse afídeo fez parte de um complexo de presas oferecidas. O tamanho da presa pode influenciar o comportamento do predador (CARVALHO e SOUZA, 2000), o que possivelmente explica a preferência de larvas de C. plorabunda por R. padi. 


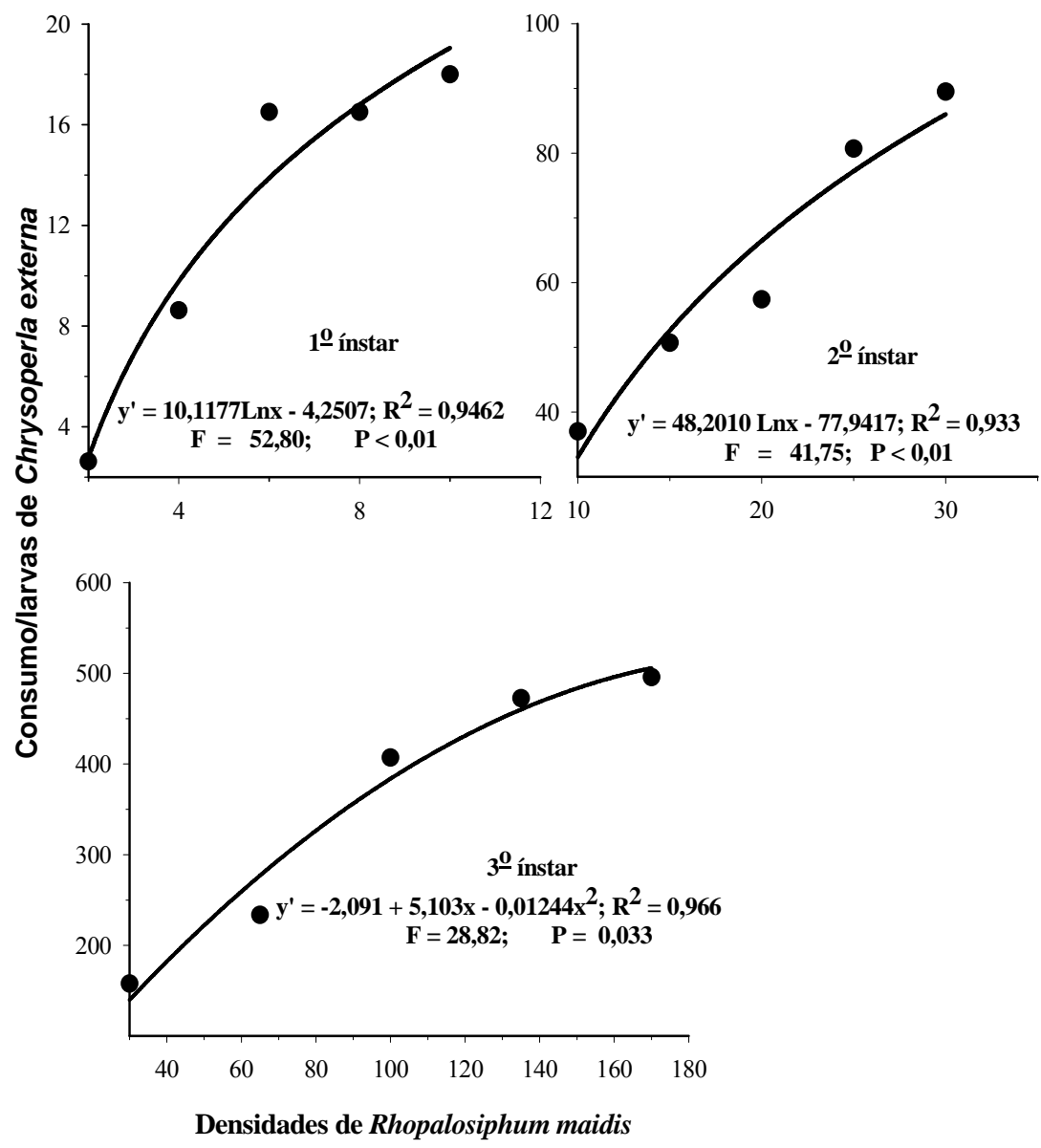

FIGURA 6 - Resposta funcional dos três ínstares de Chrysoperla externa em função da densidade de Rhopalosiphum maidis. Temperatura de $25 \pm 1{ }^{\circ} \mathrm{C}$, UR $70 \pm 10 \%$ e fotofase de 12 horas.

\section{CONCLUSÕES}

a) O consumo de presas por larvas de primeiro ínstar C. externa foi menor nas primeiras 24 horas. No segundo e terceiro instares, o consumo de presa foi maior a 24 horas do que a 48 horas;

b) Do número total de pulgões consumidos por larvas de C. externa, cerca de 77,4\% ocorreram no terceiro ínstar. Durante o ciclo larval, o consumo médio foi de 341 ou 481,6 pulgões, em função da maior densidade de presa;

c) A densidade de presas afetou a duração das fases e estádios larvais de C. externa;

d) A resposta funcional de larvas de primeiro, segundo e terceiro ínstares de C. externa foi em forma de ascensão linear, caracterizando uma resposta funcional Tipo II; e) Os tempos de busca e de manuseio foram afetados pela densidade de presas e estádio de desenvolvimento das larvas de C. externa, sendo maior no primeiro ínstar.

\section{REFERÊNCIAS BIBLIOGRÁFICAS}

ALBUQUERQUE, G. S.; TAUBER, C. A.; TAUBER, M. J. Chrysoperla externa (Neuroptera: Chrysopidae): life history and potential for biological control in Central and South America. Biological Control, Orlando, v. 4, n. 1, p. 8-13, 1994.

ALBUQUERQUE, G. S.; TAUBER, C. A.; TAUBER, M. J. Chrysoperla externa and Ceraeochrysa spp.: potential for biological control in the New World tropics and subtropics. In: McEWEN, P.; NEW, T. R.; WHITTINGTON, A. E. (Eds.). Lacewings in the crop environment. Cambridge: Academic, 2001. 546 p. 
BERGESON, E.; MESSINA, F. J. Effect of a cooccurring aphid on the susceptibility of the Russian wheat aphid to lacewings predators. Entomologia Experimentalis et Applicata, Dordrecht, v. 87, p. 103$108,1998$.

BROOKS, S. J. A taxonomic review of the common green lacewing genus Chrysoperla (Neuroptera: Chrysopidae). Bulletin of the British Museum Natural History (Entomology), Farnham Royal, v. 63, n. 2, p. 137-210, 1994.

CANARD, M. Incidences de la valeur alimentaire de divers pucerons (Homoptera: Aphididae) sur le potentiel de multiplication de Chrysopa perla (L.) (Neuroptera: Chrysopidae). Annales de Zoologie Écologie Animale, Paris, v. 2, n. 3, p. 345-355, 1970.

CANARD, M. Influence de l'alimentacion sur le dévelopment, la fécondité et la fertilité d'un prédateur aphidiphage: Chrysopa perla (Linnaeus) (Neuroptera: Chrysopidae). 1973. 175 f. Thèse (Doctorat d'État) Université Paul-Sabatier 547, Toulouse, 1973.

CARVALHO, C. F.; SOUZA, B. Métodos de criação e produção de crisopídeos. In: BUENO, V. H. P. (Ed.). Controle biológico de pragas: produção massal e controle de qualidade. Lavras: UFLA, 2000. cap. 6, p. 91-110.

CARVAlHO, C. F.; SOUZA, B.; SANTOS, T. M. Predation capacity and reproduction potential of Chrysoperla externa (Hagen) (Neuroptera: Chrysopidae) fed on Alabama argillacea (Hübner) eggs. Acta Zoologica Fennica, Helsinki, v. 209, p. 83-86, 1998.

CHAKRABARTI, S.; DEBNATH, N.; GHOSH, D. Developmental rate, larval voracity and oviposition of Cunctochrysa jubigensis (Neuroptera: Chrysopidae), an aphidophagous predator in the western Himalayas. In: POLGAR, L. et al. (Eds.). Behavior and impact of aphidophaga. Netherlands: Academic, 1991. p. 107-113.

DAANE, K. M. Ecological studies of released lacewings in crops. In: McEWEN, P.; NEW, T. R.; WHITTINGTON, A. E. (Eds.). Lacewings in the crop environment. Cambridge: Academic, 2001. cap. 14, p. 338-350.

EVERLY, R. T. Loss in corn yield associated with the abundance of the corn leaf aphid, Rhopalosiphum maidis, in Indiana. Journal of Economic Entomology, College Park, v. 53, n. 5, p. 924-932, 1960.
FONSECA, A. R. Efeitos de genótipos resistentes de sorgo e Chrysoperla extern a (Hagen, 1861) (Neuroptera: Chrysopidae) sobre Rhopalosiphum maidis (Fitch, 1856) (Hemiptera: Aphididae). 2002. 142 p. Tese (Doutorado em Entomologia) - Universidade Federal de Lavras, Lavras, 2002.

FONSECA, A. R.; CARVALHO, C. F.; SOUZA, B. Resposta funcional de Chrysoperla externa (Hagen) (Neuroptera: Chrysopidae) alimentada com Schizaphis graminum (Rondani) (Hemiptera: Aphididae). Anais da Sociedade Entomológica do Brasil, Jaboticabal, v. 29, n. 2 , p. 309-317, 2000.

GARCIA, M. A. Ecologia nutricional de parasitóides e predadores terrestres. In: PANIZZI, A. R.; PARRA, J. R. P. (Eds.). Ecologia nutricional de insetos e suas implicações no manejo de pragas. São Paulo: Manole, 1990. p. 289-311.

GASSEN, D. N. Manejo de pragas associadas à cultura do milho. Passo Fundo: Aldeia Norte, 1996. $134 \mathrm{p}$.

HOLLING, C. S. Some characteristics of simple types of predation and parasitism. The Canadian Entomologist, Ottawa, v. 91, n. 7, p. 385-398, 1959.

HOLLING, C. S. Principles of insect predation. Annual Review of Entomology, Stanford, v. 6, p. 163$182,1961$.

HŎNEK, A. Host plant energy allocation to and within ears, and abundance of cereal aphids. Journal of Applied Entomology, Hamburg, v. 110, p. 68-72, 1990.

HŎNEK, A. Environment stress, plant quality and abundance of cereal aphids (Hom., Aphididae) on winter wheat. Journal of Applied Entomology, Hamburg, v. 112, p. 65-70, 1991.

KABISSA, J. C. B.; KAYUMBO, H. Y.; JULIANO, S. A. Functional responses of two chrysopid feeding on Helicoverpa armigera (Lepidoptera: Noctuidae) and Aphis gossypii (Homoptera: Aphididae). Entomophaga, Paris, v. 41, n. 2, p. 141-151, 1996.

LÓPEZ, C. C. Potencial de alimentação de Chrysoperla externa (Hagen, 1861) e Ceraeochrysa cincta (Schneider, 1851) (Neuroptera: Chrysopidae), sobre o pulgão da roseira Rhodobium porosum (Sanderson, 1900) (Hemiptera: Aphididae). 1996. 86 f. Dissertação (Mestrado em Agronomia) - Universidade Estadual de São Paulo, Jaboticabal, 1996. 
MAGALHÃES, P. C.; DURÃES, F. O. M.; PAIVA, E. Fisiologia da planta de milho. Sete Lagoas: EMBRAPA/ CNPMS, 1995. 27 p. (Circular técnica, 20).

MAIA, W. J. M. S.; CARVALHO, C. F.; SOUZA, B. Exigências térmicas de Chrysoperla externa (Hagen, 1861) (Neuroptera: Chrysopidae) alimentada com Schizaphis graminum (Rondani, 1852) (Hemiptera: Aphididae) em condições de laboratório. Ciência e Agrotecnologia, Lavras, v. 24, n. 1, p. 81-86, 2000.

NORDLUNG, D. A.; MORRISON, M. J. Handling time, prey preference, and functional response for Chrysoperla rufilabris in the laboratory. Entomologia Experimentalis et Applicata, Dordrecht, v. 57, p. 237242, 1990.

O'NEIL, R. J. Functional response of arthropod predators and its role in the biological control of insects pests in agricultural systems. In: New direction in biological control: alternatives for suppressing agricultural pests and diseases. New York: Academic, 1990. p. 83-86.

RIBEIRO, M. J. Biologia de Chrysoperla externa (Hagen, 1861) (Neuroptera: Chrysopidae) alimenta- da com diferentes dietas. 1988. 131 f. Dissertação (Mestrado em Agronomia) - Escola Superior de Agricultura de Lavras, Lavras, 1988.

SANTA-CECÍLIA, L. V. C. et al. Aspectos biológicos das fases imaturas de Chrysoperla externa (Hagen, 1861) (Neuroptera: Chrysopidae) alimentada com Dysmicoccus brevipes (Cockerell, 1893) (Hemiptera: Pseudococcidae). In: SIMPÓSIO DE CONTROLE BIOLÓGICO, 7., 2001, Poços de Caldas. Resumos... Lavras: UFLA, 2001. p. 28.

SENIOR, L. J.; McEWEN, P. K. The use of lacewings in biological control. In: McEWEN, P.; NEW, T. R.; WHITTINGTON, A. E. (Eds.). Lacewings in the crop environment. Cambridge: Academic, 2001. cap. 11, p. 296-302.

SOLOMON, M. E. The natural control of animal populations. Journal of Animal Ecology, Oxford, v. 18, p. 1-35, 1949.

ZHENG, Y. et al. Influence of larval food consumption on the fecundity of the lacewing Chrysoperla carnea. Entomologia Experimentalis et Applicata, Dordrecht, v. 67, p. 9-14, 1993. 